\title{
A RETROSPECTIVE STUDY ON THYROID GLAND LESIONS ASSOCIATED WITH MULTI-NODULAR GOITRE
}

\author{
Priya P. V1, Elvin Merin Cherian²
}

${ }^{1}$ Associate Professor, Department of Pathology, Government Medical College, Gandhinagar.

2Junior Resident, Department of Pathology, Government Medical College, Gandhinagar.

\begin{abstract}
\section{BACKGROUND}

Nodular enlargement of thyroid gland is a frequent surgical problem worldwide and it is most often caused by nodular hyperplasia due to impaired synthesis of thyroid hormone. An autonomous nodule may develop in $10 \%$ of long-standing multi-nodular goitre and produce hyperthyroidism. Sometimes nodular hyperplasia displays features that may be confused for a neoplastic process.

The aim of this study is to find out the frequency of different types of non-neoplastic and neoplastic thyroid lesions developing in association with multi-nodular goitre.
\end{abstract}

\section{MATERIALS AND METHODS}

All thyroidectomy specimens received in our Institution from January 2011 to December 2015 and which showed multi-nodular hyperplasia on histopathological examination were included.

\section{RESULT}

Nodular hyperplasia either alone or in combination with any other thyroid lesion was observed in $70.8 \%(\mathrm{n}=1529)$ of the total thyroidectomy specimens. Chronic lymphocytic thyroiditis was observed in $12.7 \%$ cases and important tumour-like thyroid lesions observed were cellular nodule (6.2\%), Hurthle cell nodule $(0.5 \%)$, papillary hyperplasia $(0.5 \%)$ and pseudo-nuclear clearing $(0.1 \%)$. Important thyroid neoplasms observed in association with multi-nodular goitre were Papillary carcinoma (3\%), Hurthle cell adenoma (0.5\%), Follicular adenoma $(0.2 \%)$ and Medullary carcinoma $(0.1 \%)$. Incidence rate of thyroid malignancy in association with nodular hyperplasia was $3.8 \%$.

\section{CONCLUSION}

More than two-third of the neoplasms observed were papillary micro-carcinomas; this highlights the importance of thorough sampling of thyroidectomy specimens. However, comparatively thyroid neoplasms in nodular hyperplasia had a lower incidence rate in this study and the peak incidence of nodular hyperplasia associated papillary carcinoma was in younger age group. This difference may be attributed to improved public awareness and health welfare facilities available in Kerala.

\section{KEYWORDS}

Thyroid Gland, Nodular Goitre, Nodular Hyperplasia, Thyroiditis, Thyroid Neoplasm.

HOW TO CITE THIS ARTICLE: Priya PV, Cherian EM. A retrospective study on thyroid gland lesions associated with multi-nodular goitre. J. Evolution Med. Dent. Sci. 2017;6(7):540-544, DOI: 10.14260/Jemds/2017/115

\section{BACKGROUND \\ Thyroid gland enlargement in the form of solitary or multi- nodular or diffuse is a frequent surgical problem worldwide. It is reported that the prevalence of palpable thyroid nodules in two separate non-biased population based studies in Unites States and England was $4.2 \%$ and $3.2 \%$ respectively. ${ }^{[1,2]}$ According to a report from Mayo Clinic, they found thyroid nodules in $50.5 \%$ of the consecutive autopsies of patients with clinically normal thyroid gland.[3] In India too there is a significant burden of palpable thyroid nodules. The prevalence of thyroid nodules may vary with age, gender and population studied. Thyroid nodules are frequently seen in adults and female gender.[4] A multitude of pathological conditions of thyroid are manifested by nodules.}

Financial or Other, Competing Interest: None.

Submission 16-12-2016, Peer Review 10-01-2017,

Acceptance 16-01-2017, Published 23-01-2017.

Corresponding Author:

Dr. Priya P. V

Associate Professor,

Department of Pathology,

Government Medical College,

Gandhinagar P. O., Kottayam.

E-mail: drpvpriya@yahoo.com

DOI: $10.14260 /$ jemds $/ 2017 / 115$
These range from non-neoplastic nodules including nodular goitre and chronic lymphocytic thyroiditis to neoplastic diseases of follicular or parafollicular origin as well as metastases.[5] Ultrasonography has an important role in detecting actual number of nodules; this information has clinical significance for further management. A palpable solitary nodule represents a multinodular gland in about 35\% of patients.[6]

Nodular enlargement of thyroid is most often caused by nodular hyperplasia due to impaired synthesis of thyroid hormone. The degree of thyroid gland enlargement is proportional to the level and duration of thyroid hormone deficiency. During the initial stage of hormone deficiency, a diffuse enlargement of entire thyroid gland due to hyperplasia takes place (simple goitre). Virtually, all longstanding simple goitres of both sporadic and endemic types convert into a multi-nodular goitre (Nodular hyperplasia), which is more frequently mistaken for neoplasms. ${ }^{[7]}$ Diffuse goitre and multi-nodular goitre are said to be endemic when these affect more than $5 \%$ and $10 \%$ of a given population respectively.[7,8]

In India critical researches during twentieth century has resulted in endemic goitre being reported from all over the country and not just from the Himalayan and sub-Himalayan 
region. [9] Apart from the cosmetic problems and pressure effects due to enlarged thyroid, an autonomous nodule may develop in $10 \%$ of long-standing multi-nodular goitre and produce hyperthyroidism.[7] Clonal analysis showed that, both polyclonal and monoclonal nodules may coexist in the multi-nodular goitre and that monoclonal nodules can originate from different cells. This suggests that different mechanisms occur simultaneously or that monoclonal nodules emerge secondarily from a polyclonal population due to a growth advantage from a genetically altered cell. [10,11]

Microscopically, a wide range of appearances may be seen in multi-nodular goitre (Nodular hyperplasia). Some nodules have huge follicles lined by flattened epithelium, others are extremely cellular and hyperplastic and still others are composed exclusively of Hurthle cells. Although foci of haemorrhage, foreign body giant cell reaction, calcification, fibrosis and osseous metaplasia are frequent in nodular hyperplasia, presence of hyperplastic follicles within vascular lumina and foci of extramedullary haematopoiesis are exceptional.[10,12,13] A variable number of lymphocytes may be present in the stroma indicating the coexistence of chronic thyroiditis. It is not possible to predict on the basis of morphology alone whether the patient has clinical or laboratory evidence of hyperthyroidism.[14]

Sometimes nodular hyperplasia displays features that may be confused for a neoplastic process. Awareness of such features and their recognition are of prime importance to avoid misdiagnosis of a thyroid neoplasm. Marked nuclear chromatin clearing can be seen in thyroid specimens owing to improper fixation.[15] Freezing of thyroid tissue usually leads to loss of nuclear detail; however, occasionally it results in artificial nuclear clearing, grooving and inclusions. Thus it may lead to a false positive diagnosis of papillary carcinoma in frozen section of a thyroid specimen.[16] Benign papillary structures can develop in nodular hyperplasia, Hashimoto thyroiditis and Grave's disease. Papillary projections in dilated follicles of nodular hyperplasia may be confused with papillary carcinoma.[15] Microscopic distinction between a dominant (Cellular) nodule of nodular hyperplasia and a true adenoma is not reliable.[16] Many recent studies have shown that thyroid malignancy can occur in multi-nodular goitre. Review of literature showed that the most frequent histological subtype of thyroid cancer found in nodular hyperplasia was papillary carcinoma.[17,18,19] It is also well documented that both Hurthle cell nodules and neoplasms may originate within multi-nodular goitre and majority are benign lesions.[20]

\section{Aim}

Our study was aimed to find out the frequency of different types of non-neoplastic and neoplastic thyroid lesions developing in association with nodular hyperplasia (multinodular goitre) of thyroid gland.

\section{MATERIALS AND METHODS}

It is a retrospective study carried out in the Department of Pathology in a Tertiary Care Teaching Centre. Inclusion criteria: All thyroidectomy specimens which showed evidence of multi-nodular goitre on histopathological examination done in the Department of Pathology from January 2011 to December 2015. Exclusion criteria: Cases with solitary nodule of thyroid, simple hyperplasia of thyroid and past history of any type of thyroidectomy or thyroid neoplasms. Data including patient's age, sex, surgical treatment type and histopathological diagnosis were collected from the records. The spectrum of non-neoplastic and neoplastic lesions developing in association with nodular hyperplasia of thyroid in relation to age and gender of patients was studied using the data collected. The collected data were analysed by SPSS package 16.0.

\section{RESULTS}

In our centre, during the study period a total of 2160 thyroid specimens were subjected to histopathologic examination which is the gold standard method for the diagnosis of thyroid gland pathology. Thyroidectomy specimens constituted $3.6 \%$ of the total 60310 surgical specimens received during the study period in the Department of Pathology. On histopathological examination, evidences of nodular hyperplasia either alone or in combination with any other thyroid lesion were observed in 1529 cases, which include 110 near total thyroidectomy, 15 subtotal thyroidectomy, 1267 total thyroidectomy and 137 hemithyroidectomy specimens. The frequency of nodular hyperplasia of thyroid gland in relation to total thyroid specimens received each year during the study period is shown in Table 1. Distribution of nodular hyperplasia according to age and gender are depicted in Table 2 . It is observed that $62.6 \%$ of the cases belonged to middle age group with a peak in the age group of 40 - 49 years (35.9\%, $\mathrm{n}=549$ ). This value was found to be statistically significant ( $P$ $<0.005$ ). Six cases of nodular hyperplasia showed areas with Hurthle cell change in follicular epithelium along with dense lymphocytic infiltration in stroma. Evidence of associated chronic lymphocytic thyroiditis was observed in 194 cases. Table 3 shows the frequency of tumour-like lesions and tumours of thyroid gland which were seen in association with nodular hyperplasia. The commonest tumour-like lesion was cellular nodule. Both malignant and benign thyroid neoplasms were observed in association with nodular hyperplasia. Among the 46 papillary carcinoma cases, we observed 34 cases belonged to papillary micro-carcinomas and rest were contributed by 3 cases of classical papillary carcinoma, 1 case of follicular variant of papillary carcinoma and 8 cases of multi-centric papillary carcinoma.

\begin{tabular}{|c|c|c|c|}
\hline Year & Total Thyroid Specimens & Multi-Nodular Hyperplasia & Valid Percent \\
\hline 2011 & 361 & $255(70.6 \%)$ & 16.7 \\
\hline 2012 & 437 & $312(71.3 \%)$ & 20.4 \\
\hline 2013 & 455 & $322(70.7 \%)$ & 21.1 \\
\hline 2014 & 412 & $300(72.8 \%)$ & 19.6 \\
\hline 2015 & 495 & $340(68.6 \%)$ & 22.2 \\
\hline TOTAL & $\mathbf{2 1 6 0}$ & $\mathbf{1 5 2 9}(\mathbf{7 0 . 8} \%)$ & $\mathbf{1 0 0 . 0}$ \\
\hline \multicolumn{4}{|r}{} \\
\hline
\end{tabular}




\begin{tabular}{|c|c|c|c|c|c|c|c|c|c|c|c|}
\hline \multirow[b]{2}{*}{ Gender } & \multicolumn{10}{|c|}{ Age in Years } & \multirow[b]{2}{*}{ Total } \\
\hline & $<10$ & $10-19$ & 29-29 & 30-39 & $40-49$ & 50-59 & 60-69 & 70-79 & 80-89 & $89<$ & \\
\hline Male & 1 & 2 & 6 & 31 & 62 & 35 & 28 & 7 & 1 & 0 & 173 \\
\hline Female & 0 & 10 & 67 & 378 & 487 & 258 & 137 & 16 & 2 & 1 & 1356 \\
\hline Total & 1 & 12 & 73 & 409 & 549 & 293 & 165 & 23 & 3 & 1 & 1529 \\
\hline
\end{tabular}

\begin{tabular}{|c|c|c|c|}
\hline \multicolumn{2}{|c|}{ Lesions } & Number & $\begin{array}{l}\text { Valid \% } \\
(n=1529)\end{array}$ \\
\hline \multirow{4}{*}{$\begin{array}{l}\text { Tumour- } \\
\text { Like } \\
\text { Lesions }\end{array}$} & Cellular nodule & 95 & 6.2 \\
\hline & $\begin{array}{l}\text { Hurthle cell } \\
\text { nodule }\end{array}$ & 7 & 0.5 \\
\hline & $\begin{array}{c}\text { Papillary } \\
\text { hyperplasia }\end{array}$ & 8 & 0.5 \\
\hline & Nuclear clearing & 1 & 0.1 \\
\hline \multirow{4}{*}{ Tumours } & $\begin{array}{l}\text { Follicular } \\
\text { adenoma }\end{array}$ & 4 & 0.2 \\
\hline & $\begin{array}{l}\text { Hurthle cell } \\
\text { adenoma }\end{array}$ & 7 & 0.5 \\
\hline & $\begin{array}{l}\text { Papillary } \\
\text { carcinoma }\end{array}$ & 46 & 3.0 \\
\hline & $\begin{array}{l}\text { Medullary } \\
\text { carcinoma }\end{array}$ & 1 & 0.1 \\
\hline \multicolumn{4}{|c|}{$\begin{array}{l}\text { Table 3. Frequency of Tumour-Like Lesions and Tumours } \\
\text { in Multi-Nodular Hyperplasia }\end{array}$} \\
\hline
\end{tabular}

\section{DISCUSSION}

In this study, histopathological evidence of multi-nodular goitre (Nodular hyperplasia) was present in $70.8 \%$ ( $\mathrm{n}=$ 1529) of the total thyroidectomy specimens received during the study period. Studies from other parts of India[21,22] also showed the dominance of nodular hyperplasia among thyroid pathology. This highlights that, even after the three decades of mandatory iodisation of salt since 1986[23] nodular hyperplasia still remains as the most common thyroid pathology in India. A wide range of age distribution was noted in the case of nodular hyperplasia of thyroid with a mean age of $45 \pm 11$ years. An 8-year-old male child was on one end of this spectrum and a 90-year-old lady on the other end. Maximum number of cases were in the age group of 40 49 years followed by 30 - 39 years, which account for $35.9 \%$ $(n=549)$ and $26.7 \%(n=409)$ respectively. Consistent with previous reports,[21,22] a significant female preponderance was observed in this study too with a female-to-male ratio of 7.8:1.

Histological evidence of chronic lymphocytic thyroiditis was observed in $12.7 \%(n=194)$ of nodular hyperplasia and $95.8 \%$ of which were females, it was found to be statistically significant $(\mathrm{P}=<0.005)$. It is also noted that during the study period, the incidence of chronic lymphocytic thyroiditis in nodular hyperplasia was gradually increasing in successive years from $8.2 \%$ in 2011 to $13.2 \%$ in 2015. In 6 cases (0.4\%) of nodular hyperplasia, areas resembling Hashimoto thyroiditis were present and all of them were females. It is well documented that more the number of chronic inflammatory cells, higher the incidence of postoperative hypothyroidism. ${ }^{[7]}$

Sometimes a hyperplastic nodule may show central cystic degeneration and pseudopapillary or papillary fronds in the wall, which can resemble a thyroid neoplasm such as an encapsulated variant of papillary thyroid carcinoma or follicular adenoma with papillary hyperplasia. Currently, the diagnosis of papillary carcinoma is more dependent upon characteristic nuclear features than on the papillary architecture. Absence of cells with centrally located optically clear nucleus having thick nuclear membrane and presence of pale vacuolated colloid helps to differentiate such nonneoplastic papillary fronds from papillary thyroid carcinoma. ${ }^{[10,24]}$ In this study, such non-neoplastic papillary fronds were observed in $0.5 \%(n=8)$ cases of nodular hyperplasia. Any delay in fixation, inadequate amounts of fixative, placing the entire thyroid specimen in fixative without sectioning or "bread loafing" are the described causes for pseudo clearing of nucleus in thyroid lesions and it causes resemblance to papillary thyroid carcinoma.[15] In this study, single case of nodular hyperplasia showed pseudo clearing of nucleus.

The distinction between a cellular nodule in nodular hyperplasia and follicular adenoma of thyroid is sometimes rather arbitrary. In general cellular nodules are multiple; lack a well-defined complete fibrous capsule and have an architectural and cytologic feature similar to those of the surrounding gland, which do not show signs of compression.[10,24] In this study, 6.2\% ( $\mathrm{n}=95)$ cases of nodular hyperplasia showed cellular nodule and majority of them $(85 \%, n=81)$ were females. Another $0.5 \%(n=7)$ cases showed a nodule completely consisting of Hurthle cells, which were reported as multi-nodular hyperplasia with Hurthle cell nodule.

Recent studies have shown that thyroid neoplasm can occur in nodular hyperplasia, but whether nodular hyperplasia is associated with an increased risk of thyroid malignancy is still remaining as a topic for debate. It is documented that in iodine deficient areas, nodular hyperplasia has association with follicular carcinoma. ${ }^{24]}$ The incidence rate of thyroid malignancy in nodular goitre was $10 \%$ in two separate recent studies reported in 2012 by Hanumanthappa et al[25] and in 2013 by Nadeem et al[17] from India and Pakistan respectively, in both the most common histological type of thyroid malignancy observed was papillary carcinoma. In the current study there were 11 benign and 47 malignant thyroid neoplasms developed in association with nodular hyperplasia, so the incidence rate of thyroid malignancy was only $3.8 \%(n=47)$, which was comparatively lesser than the other two previous studies.[17,25] No significant association was observed between the development of thyroid malignancy and lymphocytic thyroiditis in nodular hyperplasia.

In the present study also papillary carcinoma outstands (97.8\%, n=46) among the different types of thyroid malignancies and majority of which were in female gender $(82.6 \%, n=38)$ and middle age group, these observations were corroborated with that of Hanumanthappa et al[25] who had also reported similar findings. Peak incidence of nodular hyperplasia associated papillary carcinoma was noted in the age group of 30 - 39 years (34.7\%) followed by 40 - 49 years $(30.4 \%)$. But the peak incidence of papillary carcinoma was 
in the age group of 41 - 50 years in the other two previous reports.[17,25]

Among the different histological variants of papillary carcinoma observed in association with nodular hyperplasia in the current study, majority were papillary microcarcinomas $(73.9 \%, \mathrm{n}=34)$ and $67.6 \%$ of which were in the age range of 30 - 49 years. Papillary micro-carcinoma is defined as a papillary carcinoma measuring 1 centimeter or less in diameter. It is a frequent incidental finding in autopsy studies. Detection of papillary micro-carcinoma in thyroid gland depends on thoroughness of the histopathological examination.[10] It is also reported that the papillary microcarcinomas classically progress to a clinically evident disease if they are left untreated.[25] In the current study, 0.5\% (n= 8) of papillary carcinomas showed multiple microscopic foci of papillary carcinomas. It is documented that in about $20 \%$ of papillary carcinomas multiple microscopic foci of tumour are found if a few random sections of thyroid gland are examined. Controversy still exists as to whether this represents multicentricity or intra-thyroidal lymphatic permeation.[10]

Follicular adenoma was observed in 4 cases in association with nodular hyperplasia and all were in the age group above 49 years with female predominance $(75 \%)$. Hurthle cell adenoma was observed in 7 cases in association with nodular hyperplasia and had a wider range of age distribution from 20 to 59 years.

\section{CONCLUSION}

This study highlights that in India even after the three decades of mandatory iodisation of salt since 1986[23] multinodular goitre (Nodular hyperplasia) still remains as the most common thyroid pathology and indication for thyroidectomy. Peak incidence of nodular hyperplasia was in the age group of $40-49$ years $(35.9 \%, n=549)$ and frequency was higher in female gender. Chronic lymphocytic thyroiditis was seen in $12.7 \%(n=194)$ cases of nodular hyperplasia with a statistically significant association with female gender ( $\mathrm{p}=<0.005$ ). The commonest mimicker of thyroid neoplasm seen in association with nodular hyperplasia was cellular nodule $(6.2 \%, \mathrm{n}=95)$. Non-neoplastic papillary fronds and pseudo clearing of nucleus, which mimics papillary thyroid carcinoma were also observed in a small percentage of cases of nodular hyperplasia. So, the diagnosis of papillary carcinoma should be considered only when all major cytologic features are seen in the thyroid lesion.

Papillary carcinoma was detected in $3 \%$ cases of nodular hyperplasia and which was the commonest $(97.8 \%)$ thyroid malignancy noted. More than two-third of these were papillary micro-carcinomas, which highlights the importance of proper gross study and thorough sampling of thyroidectomy specimens. However, in this study incidence rate of thyroid neoplasms in association with nodular hyperplasia was lower and the peak incidence of papillary carcinoma was in younger age group when compared to other studies.[17,25] This difference may be due to the improvement in public awareness and health welfare facilities available in Kerala.

\section{Acknowledgement}

We would like to acknowledge the Head of the Department of Pathology and all consultant surgeons of our Institution for providing material for this study. There is no conflict of interest, which is associated with this publication and that there has been no financial support for this work that could have influenced its outcome.

\section{REFERENCES}

[1] Vander JB, Gaston EA, Dawber TR. The significance of nontoxic thyroid nodules. Final report of a 15-year study of the incidence of thyroid malignancy. Ann Intern Med 1968;69(3):537-40.

[2] Turnbridge WM, Evered DC, Hall R, et al. The spectrum of thyroid disease in a community: the Whickham survey. Clin Endocrinol 1977;7(6):481-93.

[3] Mortensen JD, Woolner LB, Bennett WA. Gross and microscopic findings in clinically normal thyroid glands. J Clin Endocrinol Metab 1955;15(10):1270-80.

[4] Ezzat S, Sarti DA, Cain DR, et al. Thyroid incidentelomas. Prevalence by palpation and ultrasonography. Arch Intern Med 1994;154(16):1838-40.

[5] Cannon J. The significance of hurthle cells in thyroid disease. The Oncologist 2011;16(10):1380-7.

[6] Padmawar MR, Kher K, Kakade A. Clinicopathological study of multinodular goier at AVBRH. IJBAR 2014;5(1):10-3.

[7] Anirban M. The endocrine system. In: Kumar V, Abbas AK, Aster JC, (edtrs). Pathologic basis of disease. vol II, 9th edn. Haryana: Reed Elsevier India Private Limited, 2015:1073-139.

[8] Khatawkar AV, Awati SM. Multi-nodular goiter: epidemiology, etiology, pathogenesis and pathology. IAIM 2015;2(9):152-6.

[9] Unnikrishnan AG, Menon UV. Thyroid disorders in India: an epidemiological perspective. Indian J Endocrinol Metab 2011;15(Suppl 2):S78-S81.

[10] Rosai J, Tallini G. Thyroid gland. In: Rosai J, (edtr). Rosai and Ackerman's surgical pathology. Vol I. 10 edn. Kundli: Reed Elsevier India Private Limited 2015:487-564.

[11] Baloch ZW, LiVolsi VA. Clonality in thyroid nodules: the hyperplasia-neoplasia sequence. Endocr Pathol 1998;9(1):287-92.

[12] Leoni F, Fabbri R, Pascarella A, et al. Extramedullary hematopoiesis in thyroid multinodular goiter preceding clinical evidence of agnogenic myeloid metaplasia. Histopathology 1996;28(6):559-61.

[13] Akbulut S, Yavuz R, Akansu B, et al. Ectopic bone formation and extramedullary hematopoiesis in the thyroid gland: report of a case and literature review. Int Surg 2011;96(3):260-5.

[14] Greene R. Lymphadenoid change in the thyroid gland and its relation to postoperative hypothyroidism. Mem Soc Endocrinol 1953;1:16-20.

[15] Baloch ZW, LiVolsi VA. Cytologic and architectural mimics of papillary thyroid carcinoma. Diagnostic challenges in fine-needle aspiration and surgical 
pathology specimens. Am J Clin Pathol 2006;125:S135-44.

[16] Faquin WC. The thyroid gland: recurring problems in histologic and cytologic evaluation. Arch Pathol Lab Med 2008;132(4):622-32.

[17] Nadeem K, Akhtar N, Tarar JM. Thyroid malignancy in multi nodular goiter; incidence, a retrospective study in southern Punjab. Professional Med J 2013;20(4):587-90.

[18] Bombil I, Bentley A, Kruger D, et al. Incidental cancer in multinodular goitre post thyroidectomy. S Afr J Surg 2014;52(1):5-9.

[19] Abdelkhalek MM. Dominant nodule within multinodular goiter: does we have to buy more attention for? AAMJ 2013;11:133-47.

[20] Montone KT, Baloch ZW, LiVolsi VA. The thyroid hurthle (oncocytic) cell and its associated pathologic conditions: a surgical pathology and cytopathology review. Arch Pathol Lab Med 2008;132(8):1241-50.
[21] Prajapati VP, Nayak JC, Desai KS, et al. Histological study of adenomatous goitre. National Journal of Integrated Research in Medicine 2012;3(2):65-8.

[22] Ejaz R, Salaria SM, Bukhari MH, et al. Histopathological spectrum of surgically treated goiters in Muzaffarabad. PJMHS 2015;9(1):2-4.

[23] Pandav CS, Yadav K, Srivastava R, et al. Iodine deficiency disorders control in India. Indian J Med Res 2013;138(3):418-33.

[24] DeLellis RA, Lloyd RV, Heitz PU, et al. World Health Organisation classification of tumors. Pathology and genetics of tumors of endocrine organs. IARC Press: Lyon 2004;49-133.

[25] Hanumanthappa MB, Gopinathan S, Rithin S, et al. The incidence of malignancy in multi-nodular goitre: a prospective study at a tertiary academic centre. JCDR 2012;6(2):267-70. 